\title{
Establishment of the dominant lethal test in the freshwater mollusk Biomphalaria glabrata (Say, 1818)
}

\author{
Eliana Nakano $^{\mathrm{a}, *}$, Liz Cristina Watanabe ${ }^{\mathrm{a}}$, Fernanda Pires Ohlweiler ${ }^{\mathrm{a}}$, \\ Carlos Alberto de Bragança Pereira ${ }^{\mathrm{b}, 1}$, Toshie Kawano ${ }^{\mathrm{a}}$ \\ ${ }^{a}$ Laboratório de Parasitologia/Malacologia, Instituto Butantan, Avenida Vital Brasil, 1500, CEP 05503-900 São Paulo, Brazil \\ ${ }^{\mathrm{b}}$ Depto de Estatistíca, Núcleo de Bioinformática, Instituto de Matemática, Universidade de São Paulo, Rua do Matão, \\ 1010, CEP 05008-090 São Paulo, Brazil
}

Received 30 May 2002; received in revised form 27 January 2003; accepted 30 January 2003

\begin{abstract}
Mutagens in the environment may represent a long-term risk for ecosystems. The reproductive potential of populations can be affected by alterations in the fecundity and offspring viability caused by germ cell mutations. Despite the ecological relevance of these effects, there are few studies on germ cell mutagenicity in natural populations. Biomphalaria glabrata was chosen for this study because of the scarcity of data on freshwater invertebrates and the ecological importance of this group. The aim of this study was to establish a germ cell mutagenicity test in B. glabrata by using a similar approach to that used in the dominant lethal test in rodents. Mitomycin $\mathrm{C}$ was used as a direct mutagen and cyclophosphamide as a mutagen that requires metabolic activation. Wild-type snails were exposed for 10 days to three concentrations of each agent and crossed with non-exposed albino snails at the end of the treatment. The total frequencies of malformations were analyzed in the offspring of wild-type snails; among the offspring of albino snails, only the heterozygous wild-type embryos were analyzed for malformations. Both agents induced germ cell mutations. The analysis of the offspring of the wild-type snails showed an effect of the exposure up to approximately 5 days after the end of the treatment with cyclophosphamide; the effect of mitomycin $\mathrm{C}$ was observed until 45 days after the end of the exposure. There was an increase in the frequencies of malformations in the wild-type offspring of the non-exposed albino snails crossed with the wild-type snails exposed to both agents. The dominant lethal test in B. glabrata proposed in this work is easy to perform, efficient, specific and sensitive in the evaluation of germ cell mutations induced by reference mutagens. The possibility of expanding its use to environmental biomonitoring studies seems very promising and worth trying.
\end{abstract}

() 2003 Elsevier Science B.V. All rights reserved.

Keywords: Freshwater mollusk; Biomphalaria; Biomonitoring; Germ-cell mutations; Dominant lethal test; Embryonic malformations

\section{Introduction}

Most toxic substances generated by industrial, agricultural and domestic activities are released into the

\footnotetext{
* Corresponding author. Tel.: +55-11-3726-7222x2158; fax: +55-11-3726-1505.

E-mail address: eliananakano@butantan.gov.br (E. Nakano).

1 Tel.: +55-11-3091-6129; fax: +55-11-3091-6130.
}

natural fresh waters [1-4]. This causes two types of concern: the effects on ecosystems and the risk for human health.

Among the effects on natural populations, short-term effects and those that lead to mutations interfering with reproduction and genetic diversity are very significant. The induction of germ cell mutations causes the most severe consequences since they can directly 
affect the reproductive potential of populations [5]. Notwithstanding the importance of this endpoint, little attention has been paid towards the detection of germ-line mutations [6-8].

Invertebrates represent more than $90 \%$ of the aquatic species. Although there is few data on metabolism, cell cycle and DNA repair processes in invertebrates, it is essential to detect possible mutagenic effects in these organisms in order to evaluate the impact of pollution on an aquatic ecosystem [9].

Freshwater mollusks of the genus Biomphalaria can be considered good indicators for biomonitoring studies [10]. The genus shows wide geographical distribution; it is represented in Brazil by 10 species [11], has low dispersion and is easily collected. Other aspects make this system a good model for laboratory studies. The snails are easy to breed, need little space, can reproduce throughout the year under controlled conditions and have a short life-span: an egg-to-egg monitoring can be done in 2 months in B. glabrata. Being a simultaneous hermaphrodite, different reactions in both sexes do not occur. Embryos also constitute a good system to study. In $B$. glabrata, adult snails lay egg-masses with 20-50 eggs almost daily. The embryonic development from egg to hatching takes about 7-9 days at $25^{\circ} \mathrm{C}$. Eggs are placed one by one in a single layer forming a transparent plurioval egg capsule, which allows the visualization of the embryos throughout development. The normal embryonic development has been described in detail $[12,13]$ and showed well-defined and easily recognizable stages, allowing the detection of morfogenetic effects. This organism has been used in our laboratory to evaluate toxic and mutagenic effects of chemical and physical agents using mortality index, alterations in embryonic development and chromosome aberrations as biomarkers [14-18].

Embryonic malformations can be used as biomarkers in mutagenicity tests, since they are one of the effects of the induction of mutations in germ cells. In order to distinguish malformations induced by mutations in germ cells from those induced by toxic or teratogenic effects, it is possible to use an approach similar to that used in the dominant lethal test in rodents [19]. In this study, we established the dominant lethal test in B. glabrata, using two known mutagens: cyclophosphamide and mitomycin $\mathrm{C}$.

\section{Materials and methods}

\subsection{Animals}

A pigmented wild-type strain of B. glabrata obtained from Barreiro (state of Minas Gerais) and a non-pigmented albino strain, originating from Amaralina (state of Bahia), reared in the laboratory over the past 14 years were used. The homozygosis of the wild-type snails was assumed based on the long period they were kept in inbreeding conditions; this was later confirmed on basis of the results of the crossings.

The colonies are maintained in plastic aquaria with filtered, dechlorinated and aerated water and fed fresh lettuce. For the experiments, animals were isolated for at least 3 weeks before the onset of the experiments in individual aquaria under the same conditions as the colonies. We used sexually mature snails at least 2 months old and with a minimal shell diameter of $10 \mathrm{~mm}$.

\subsection{Animal selection}

All snails used in the experiments were selected by previous analysis of background frequencies of embryonic malformations. Three or four egg-masses were collected from albino snails before the crossings and those with malformation frequencies above 5\% were discarded. Wild-type snails were evaluated after a crossing with albino snails before the exposure. At least 50 phenotypically wild-type embryos per animal were analyzed among the progeny of the albino snails and those with frequencies of malformations above $3 \%$ were discarded.

\subsection{Substances}

Two reference mutagens were employed: mitomycin C [50-07-7] (mitocin ${ }^{\circledR}$ injection, Bristol-Myers ${ }^{\circledR}$ Squibb) and cyclophosphamide [6055-19-2] (Purifarma).

\subsection{Exposure}

Three groups of 13 snails were exposed to aqueous solutions of cyclophosphamide at concentrations of $3.6 \times 10^{-5}, 3.6 \times 10^{-4}$ and $3.6 \times 10^{-3} \mathrm{M} ; 13$ animals served as controls. Three groups of 12 snails were 
exposed to aqueous solutions of mitomycin $\mathrm{C}$ at concentrations of $10^{-6}, 10^{-5}$ and $10^{-4} \mathrm{M} ; 12$ snails formed the control group. The choice of the test concentrations was based on the conclusions reported in laboratory studies with aquatic species. The concentrations of mitomycin $\mathrm{C}$ were adapted from those used by Shimada and Egami [7] in the dominant lethal test with the freshwater fish Oryzias latipes, while the study of Nabih and El Hamid [20] with B. alexandrina was used as reference to the experiment with cyclophosphamide. The range of concentrations was defined in preliminary experiments. Test compounds were added directly to dechlorinated filtered water at $25^{\circ} \mathrm{C}$ immediately before the exposure. Wild-type snails were individually exposed in disposable plastic flasks to the test substances for 10 days; dechlorinated filtered water was used in control groups. We used $25 \mathrm{ml}$ flasks with perforated covers to allow breathing. Cyclophosphamide solutions were renewed daily and mitomycin solutions, every 2 days. Animals were fed every 2 days with fresh lettuce during the exposure period.

\subsection{Crossing}

Twenty-four hours after the end of the exposure, each wild-type snail was paired with a non-exposed albino snail for $24 \mathrm{~h}$ in individual aquaria. After this period, animals were isolated and egg capsules were collected from albino and wild-type snails.

\subsection{Analysis of embryonic malformations}

Egg capsules were collected daily. Plastic sheets were placed on the water surface to propitiate the oviposition and egg capsules were then transferred to cell culture plates and maintained in climatic chambers at $25{ }^{\circ} \mathrm{C}$ until the end of the analysis.

Embryos were collected from the wild-type snails for 1 month in the experiment with cyclophosphamide and for 45 days in the experiment with mitomycin C. A minimum of 50 heterozygous wild-type embryos was collected per animal in at least three egg capsules, from the albino snails. Animals were maintained isolated for at least 3 weeks before the crossings in order to increase the rate of cross-fertilization.

The crossing between homozygous wild-type snails (Fig. 1b) and albino snails (Fig. 1a) produced the following types of embryos (Fig. 2):

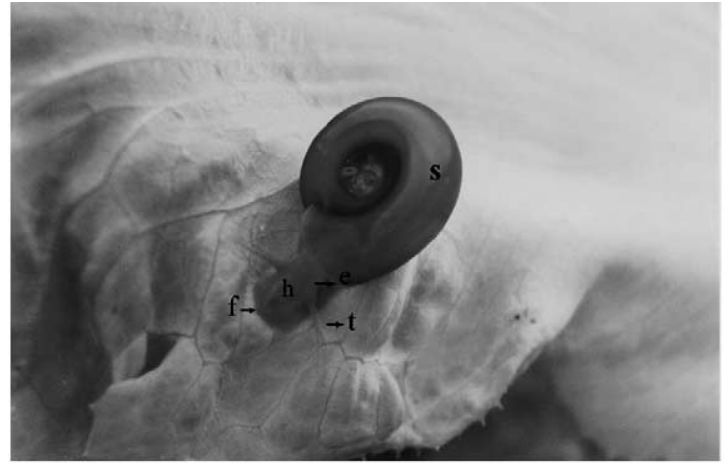

(a)

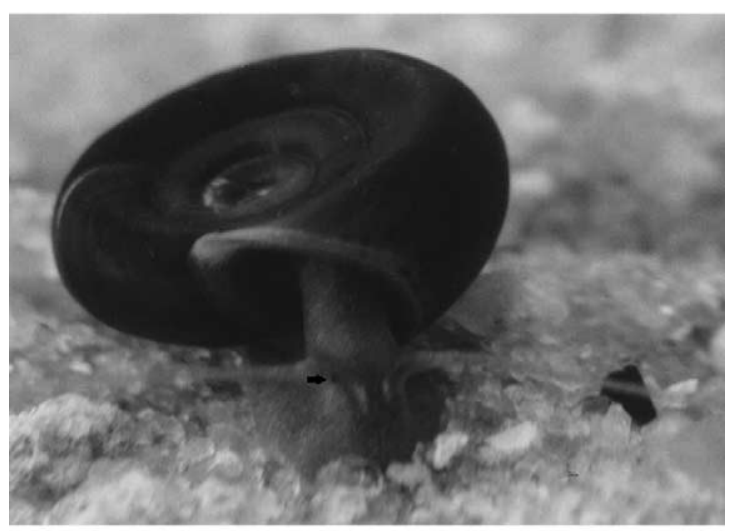

(b)

Fig. 1. B. glabrata-adult specimens. (a) Albino specimen-h: head; f: foot; s: shell; e: eye (without pigmentation); t: tentacle; (b) wild-type specimen-arrow indicating the eye.

A. Among the offspring of wild-type snails: (i) heterozygous wild-type embryos produced by cross-fertilization and (ii) homozygous wild-type embryos produced by self-fertilization or by cross-fertilization with other wild-type snails

AA - exposure

$\begin{array}{cccc}\text { Parental } & \text { AA } & \text { x } & \text { aa } \\ & \downarrow & & \downarrow \\ \text { F1:cross-fertilization } & \text { Aa } & \text { F1: cross-fertilization } & \text { Aa } \\ \text { self-fertilization } & \text { AA } & \text { self-fertilization } & \text { aa }\end{array}$

Fig. 2. Types of embryos produced after a crossing between homozygous wild-type snails and albino snails. AA, Aa and aa are the genotypes corresponding to the phenotypes wild-type pigmented, wild-type pigmented and albino non-pigmented, respectively. 
before the onset of the experiment; both types are phenotypically indistinguishable. Considering that heterozygous embryos originate from eggs of exposed wild-type snails and sperm of non-exposed albino snails and most of the homozygous, from sperm and eggs of the exposed wild-type snails, all the embryos of this offspring were analyzed.

B. Among the offspring of the albino snails: (i) heterozygous wild-type embryos produced by cross-fertilization (Fig. 3) and (ii) albino embryos produced by self-fertilization or by cross-fertilization with other albino snails before the onset of the experiment (Fig. 3). Phenotypically wild-type embryos can be identified among the offspring of albino snails by the presence of pigmentation in the eyes, visible from the fourth

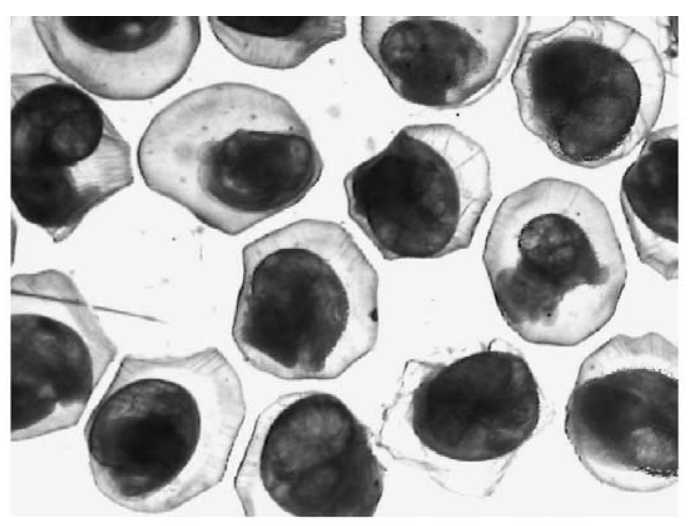

(a)

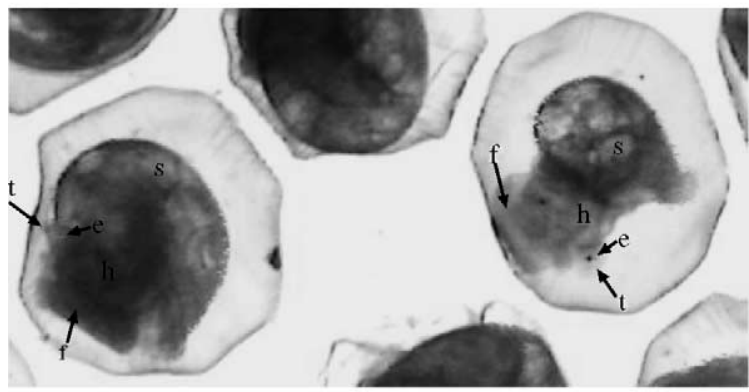

(b)

Fig. 3. (a) B. glabrata-normal wild-type and albino embryos resulting from a crossing between an homozygous wild-type snail and an albino snail; (b) detail of (a)—h: head; f: foot; s: shell; e: eye; $t$ : tentacle. day of embryonic development. Thus, we analyzed the wild-type embryos, originated from sperm of the exposed wild-type snails; albino embryos were discarded.

Embryos were observed for 8 days from the beginning of the development until nearly hatching using a stereomicroscope (Olympus). The effects on the embryonic development were classified according to Geilenkirchen [21]:

- Death: This category includes all embryos that die up to the gastrula stage (Fig. 4).

- Exogastrulation: This includes vesicular embryos, in which the invagination of the archenteron is suppressed. Embryos with these abnormalities do not develop any further and death usually ensues within a few days (Fig. 5).

- Unspecific malformations: This group includes all embryos with an abnormal development, but which cannot be described as head or shell malformations. They are, as a rule, teratomorphic or hydropic embryos. Among the offspring of albino snails, phenotypically wild-type embryos with unspecific malformations were gathered in a separate group (Fig. 6b); in the same progeny, teratomorphic embryos, in which the identification of the eyes was not possible, were classified as embryos with indeterminate malformations (Fig. 6a); albino malformed embryos (Fig. 7) were discarded.

All analyses were carried out in coded scoring.

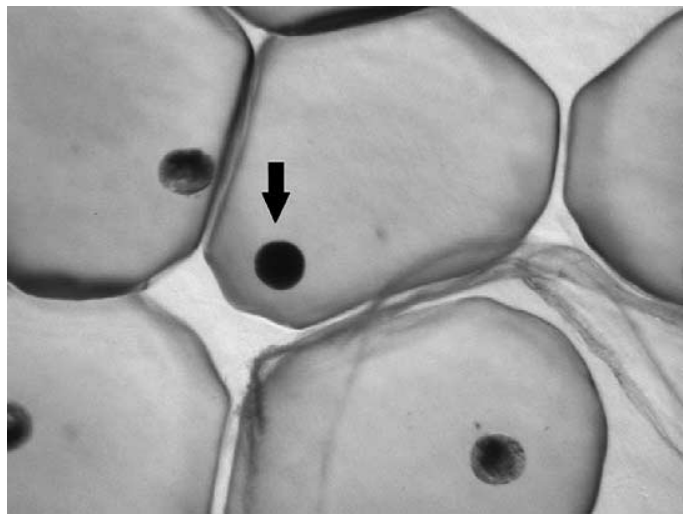

Fig. 4. Alterations in the embryonic development of B. glabrata. Dead embryo-blastula stage. 


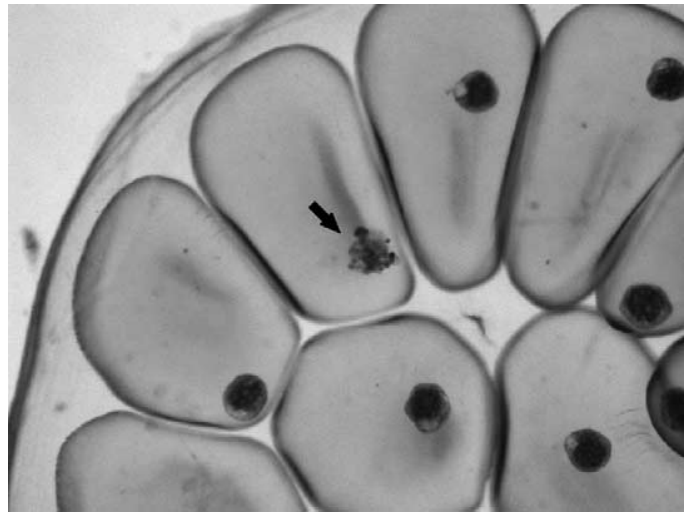

Fig. 5. Alterations in the embryonic development of B. glabrata. Exogastrulae-24 $\mathrm{h}$ after gastrulation.

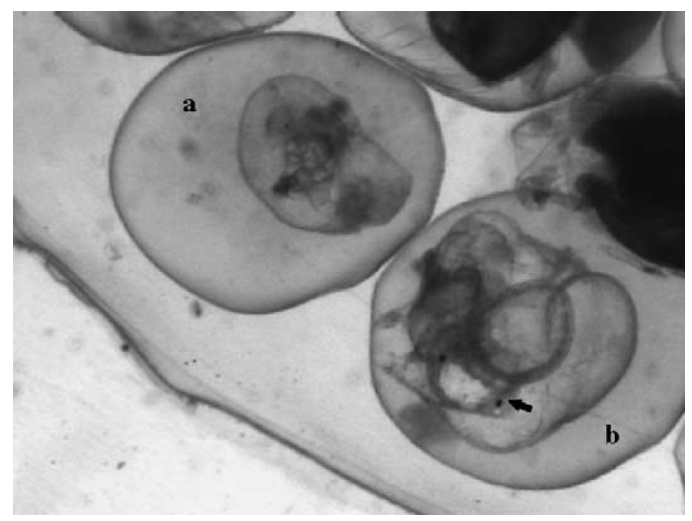

Fig. 6. Alterations in the embryonic development of B. glabrata. (a) Embryo with indeterminate malformations; (b) phenotypically wild-type malformed embryo-arrow indicating the eye.

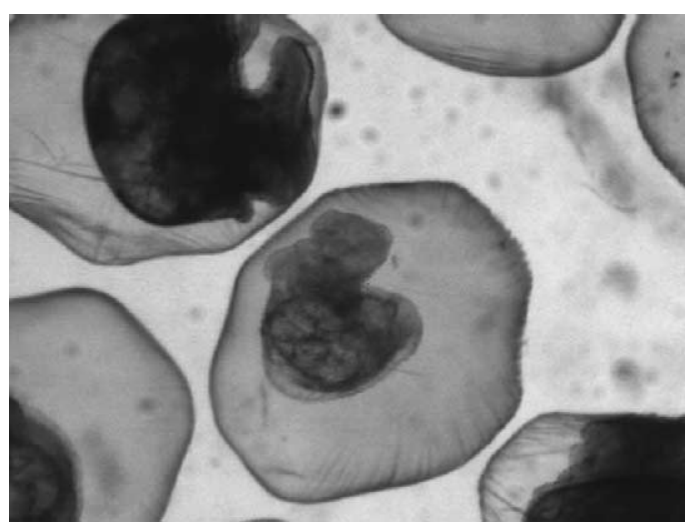

Fig. 7. Alterations in the embryonic development of B. glabrata. Albino malformed embryo.

\subsection{Statistical analysis}

To compare the malformation frequencies among the different groups the chi-square test for Poisson distributions was used. The Poisson model was considered since it has a good adjustment in presence of rare events. To illustrate the results in the wild-type offspring a temporal graph for the observed proportions of malformations was used.

\section{Results}

Results of the experiments are shown in Tables 1-3 and in the Figs. 8-10.

In all control groups, the frequencies of unviable embryos, which correspond to the total of dead and malformed embryos, were under 5\%, established as the background level to control groups in experiments with embryos of B. glabrata.

The frequencies of malformations in the heterozygous offsprings of the albino snails crossed with the wild-type snails after exposure were compared with those obtained from the crossing between albino snails and the same wild-type snails before the exposure; thus, each group served as its own control group. Among the offspring of wild-type snails, the total frequencies of dead and malformed embryos were evaluated for at least 1 month and compared among the groups.

Cyclophosphamide induced mutations in germ cells of B. glabrata at the three concentrations used. The analysis of the offspring of the wild-type snails showed an effect of the exposure up to approximately 5 days after the end of the treatment; the frequencies were higher at the two highest concentrations, but there was no dose-response effect. From that time on, until 30 days after the end of the exposure, the frequencies of malformations were equivalent in all groups (Fig. 8).

The frequencies of malformations in the offspring of the non-exposed albino snails crossed with the wild-type snails $24 \mathrm{~h}$ after the end of the exposure and in the offspring of the albino snails crossed with the same wild-type snails 5 days after the end of the exposure showed an effect of cyclophosphamide at the two highest concentrations (Tables 1 and 2). The stronger effect was observed at the first crossing and was directly proportional to the dose in both cases. 
Table 1

Frequencies of malformation in the wild-type offspring of albino snails crossed with the wild-type snails before and $24 \mathrm{~h}$ after the exposure to cyclophosphamide

\begin{tabular}{|c|c|c|c|c|c|c|c|}
\hline \multirow[t]{2}{*}{ Group } & \multirow[t]{2}{*}{ No. of animals } & \multicolumn{2}{|c|}{ No. of embryos } & \multicolumn{2}{|c|}{ Total of wild-type embryos } & \multicolumn{2}{|c|}{ No. of malformed (\%) } \\
\hline & & Before & After & Before & After & Before & After \\
\hline $\mathrm{C} 0$ & 11 & 2919 & 4564 & 2317 & 4417 & $10(0.43)$ & $35(0.79)$ \\
\hline $\mathrm{C} 1$ & 13 & 3556 & 4372 & 3435 & 4215 & $16(0.47)$ & $47(1.12)$ \\
\hline $\mathrm{C} 2$ & 10 & 2851 & 2982 & 2729 & 2625 & $10(0.37)$ & $285(10.86)^{*}$ \\
\hline C3 & 12 & 3227 & 5435 & 2189 & 933 & $16(0.73)$ & $467(50.05)^{*}$ \\
\hline
\end{tabular}

C0: control group; $\mathrm{C} 1: 3.6 \times 10^{-5} \mathrm{M} ; \mathrm{C} 2: 3.6 \times 10^{-4} \mathrm{M} ; \mathrm{C} 3: 3.6 \times 10^{-3} \mathrm{M}$.

${ }^{*} P<0.0001$.

Mitomycin C induced mutations in germ cells of $B$. glabrata at the three concentrations used. The mutagenic effects were different depending on the concentration (Table 3 and Figs. 9 and 10). In the offspring of the wild-type snails, the effect at the lowest concentration was detected only 30 days after the end of the exposure. The effects at the highest concentrationslethal to $8.33 \%(1 / 12)$ and to $33.3 \%(4 / 12)$-were ob- served from the first day until up to 45 days after the end of the exposure (Figs. 9 and 10). The comparison of time-response curves showed a dose-response effect.

The analysis of the offspring of the albino snails crossed with the wild-type ones $24 \mathrm{~h}$ after the end of the exposure showed an effect of mitomycin $\mathrm{C}$ only at the highest concentration (Table 3).

Table 2

Frequencies of malformation in the wild-type offspring of albino snails crossed with the wild-type snails before and 5 days after the exposure to cyclophosphamide

\begin{tabular}{|c|c|c|c|c|c|c|c|}
\hline \multirow[t]{2}{*}{ Group } & \multirow[t]{2}{*}{ No. of animals } & \multicolumn{2}{|c|}{ No. of embryos } & \multicolumn{2}{|c|}{ Total of wild-type embryos } & \multicolumn{2}{|c|}{ No. of malformed (\%) } \\
\hline & & Before & After & Before & After & Before & After \\
\hline $\mathrm{C} 0$ & 9 & 2348 & 3162 & 1866 & 3041 & $10(0.54)$ & $29(0.95)$ \\
\hline $\mathrm{C} 1$ & 11 & 3158 & 4012 & 3065 & 3891 & $15(0.49)$ & $31(0.79)$ \\
\hline $\mathrm{C} 2$ & 9 & 2487 & 4393 & 2412 & 4193 & $10(0.41)$ & $147(3.51)^{*}$ \\
\hline $\mathrm{C} 3$ & 12 & 3227 & 5092 & 2189 & 2823 & $16(0.73)$ & $1554(55.05)^{*}$ \\
\hline
\end{tabular}

C0: control group; $\mathrm{C} 1: 3.6 \times 10^{-5} \mathrm{M} ; \mathrm{C} 2: 3.6 \times 10^{-4} \mathrm{M} ; \mathrm{C} 3: 3.6 \times 10^{-3} \mathrm{M}$.

${ }^{*} P<0.0001$.

Table 3

Frequencies of malformation in the wild-type offspring of albino snails crossed with the wild-type snails before and $24 \mathrm{~h}$ after the exposure to mitomycin $\mathrm{C}$

\begin{tabular}{|c|c|c|c|c|c|c|c|}
\hline \multirow[t]{2}{*}{ Group } & \multirow[t]{2}{*}{ No. of animals } & \multicolumn{2}{|c|}{ No. of embryos } & \multicolumn{2}{|c|}{ Total of wild-type embryos } & \multicolumn{2}{|c|}{ No. of malformed (\%) } \\
\hline & & Before & After & Before & After & Before & After \\
\hline $\mathrm{C} 0$ & 11 & 3094 & 3058 & 2557 & 2793 & $30(1.17)$ & $25(0.89)$ \\
\hline $\mathrm{C} 1$ & 10 & 2422 & 3044 & 2032 & 2945 & $20(0.98)$ & $37(1.26)$ \\
\hline $\mathrm{C} 2$ & 9 & 1723 & 3236 & 1452 & 2940 & $23(1.58)$ & $68(2.31)$ \\
\hline $\mathrm{C} 3$ & 5 & 1530 & 2358 & 1255 & 2153 & $29(2.31)$ & $302(14.03)^{*}$ \\
\hline
\end{tabular}

C0: control group; C1: $10^{-6} \mathrm{M}$; C2: $10^{-5} \mathrm{M}$; C3: $10^{-4} \mathrm{M}$.

${ }^{*} P<0.0001$. 


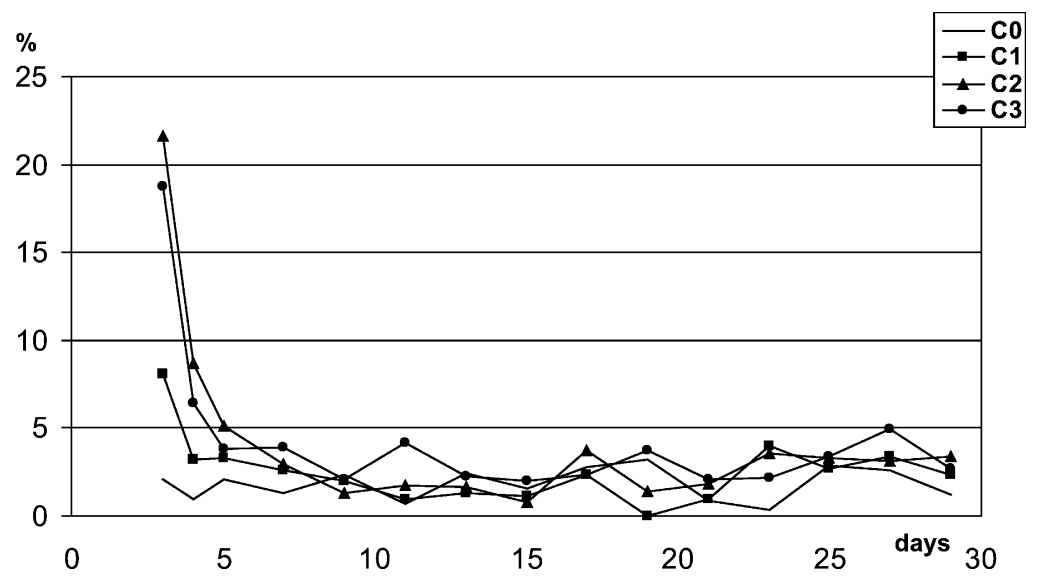

Fig. 8. Induction of malformations in B. glabrata by cyclophosphamide—offspring of wild-type snails. C0: control group; $\mathrm{C} 1$ : $3.6 \times 10^{-5} \mathrm{M}$; $\mathrm{C} 2$ : $3.6 \times 10^{-4} \mathrm{M} ; \mathrm{C} 3: 3.6 \times 10^{-3} \mathrm{M}$.

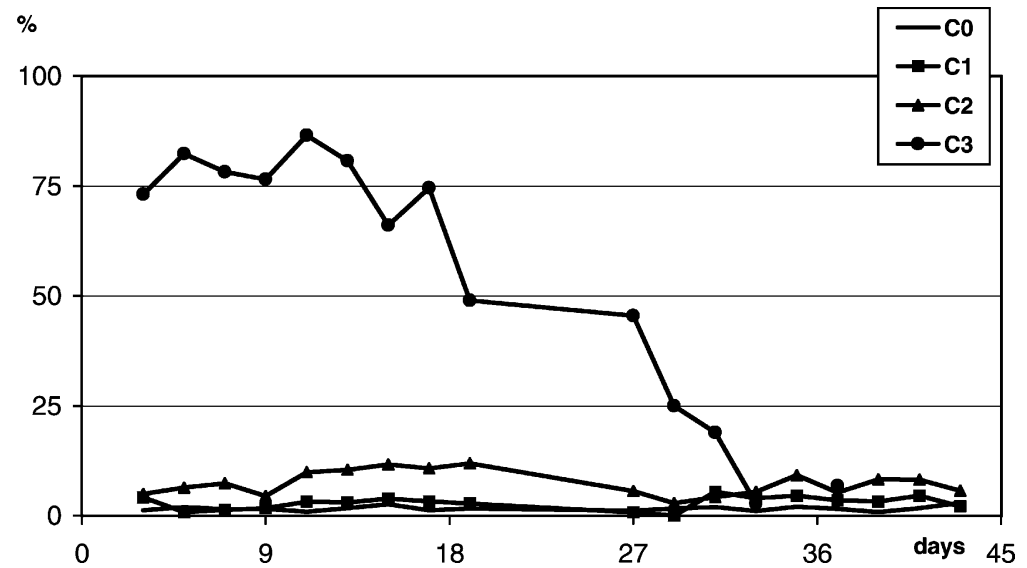

Fig. 9. Induction of malformations in B. glabrata by mitomycin $\mathrm{C}-$ offspring of wild-type snails. $\mathrm{C} 0$ : control group; $\mathrm{C} 1$ : $10^{-6} \mathrm{M}$; $\mathrm{C} 2$ : $10^{-5} \mathrm{M} ; \mathrm{C} 3: 10^{-4} \mathrm{M}$.

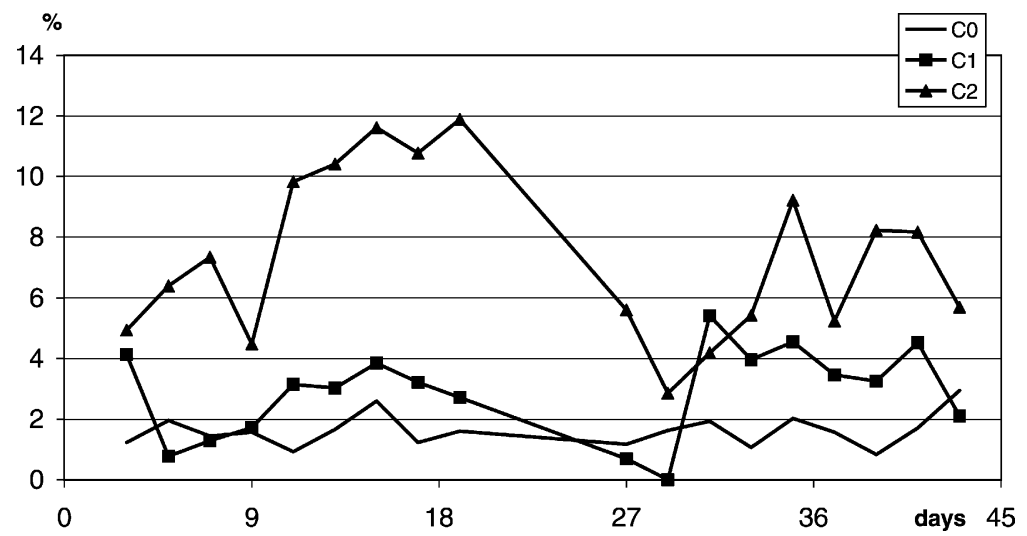

Fig. 10. Induction of malformations in B. glabrata by mitomycin C (without C3)—offspring of wild-type snails. C0: control group; C1: $10^{-6} \mathrm{M} ; \mathrm{C} 2: 10^{-5} \mathrm{M}$. 


\section{Discussion}

The analysis of embryonic malformations was used in this work to evaluate the induction of germ cell mutations. Most of the embryos with unspecific malformations, in which multiple structures are affected, die as the time of hatching approaches [22]: germ cell mutations that cause this type of malformations are, therefore, lethal mutations. The adaptation of the dominant lethal test in rodents [19] for Biomphalaria took into account the fact that the animal is a simultaneous hermaphrodite and reproduces by self- and cross-fertilization; thus, after pairing, two types of embryos are produced. In order to identify the cross-fertilization embryos, exposed homozygous wild-type snails were crossed with non-exposed albino snails; the analysis of the effects on the heterozygous embryos among the offspring of albino snails showed that the observed effects resulted, indeed, from germ cell mutations. Heterozygous wild-type embryos clearly show, around the fourth day, a black point at the base of each antenna, corresponding to the eyespots; no such points appear in homozygous albino embryos. The early appearance of the eyespots in still intracapsular embryos makes possible the speedy completion of a crossing test. Among the offspring of albino snails, pigmented embryos result from cross-fertilization, whereas albino ones result from self-fertilization [23].

In some species of egg-laying amphibians, fishes and mollusks, losses due to abortions and failures of implantation do not occur, and embryos at all stages are in proximity to their food supplies. Thus, potentially malformed embryos have the nourishment with which to grow, and this circumstance may be regarded as particularly favorable for survival up to a stage at which the potential malformations can be expressed. Furthermore, the embryos can be readily observed before hatching, because of the transparency of the outer coatings of the eggs [22]. All these advantages are displayed by $B$. glabrata, which made it possible to identify the heterozygous malformed embryos among the offspring of albino snails.

Two reference mutagens were used in this work. Mitomycin $\mathrm{C}$ was employed as a direct mutagen and cyclophosphamide, as an indirect mutagen.

The ability of metabolic activation of mutagens by some bivalve mollusks has been reported previously and it has been employed as a biomarker of exposure in pollution studies [10,24]. There are few data on gastropods, but some studies have shown that these organisms are able to activate indirect mutagens. Cyclophosphamide induced alterations on the base composition of DNA in B. alexandrina [20] and caused a reduction on DNA and RNA levels in Lymnaea acuminata [25]. In our study, the positive response obtained with cyclophosphamide demonstrates that $B$. glabrata can activate indirect mutagens. This allows the use of the test in biomonitoring of environmental mutagens, since many of them require metabolic activation.

The analysis of offspring of wild-type and albino snails served as indicators of mutagenic effects on both germ cell lineages, since in adult snails, eggs and sperm are produced in a continuous and simultaneous way from a single group of undifferentiated cells [26].

Increases in the frequencies of malformations in the albino offspring indicated the presence of mutations in the sperm of the exposed wild-type snails, since only the heterozygous embryos were analyzed among these offspring. Although the frequencies of deaths, exogastrulae and undetermined malformations were higher in the offsprings of the albino snails crossed with the exposed wild-type ones, the analysis of these endpoints did not increase the sensitivity of the test.

For the offspring of the exposed wild-type snails, we considered that the increases in the total frequencies of malformations resulted, predominantly, from the induction of mutations in the female germ cells. It is known that, in spite of the highly developed ability of $B$. glabrata to self-fertilize, it shows an absolute preference to cross-fertilization [23]. Besides, in a pairing of two snails, both act as male and female without preference to any role [27]. Thus, assuming that the rates of cross-fertilization in the wild-type snails have been of the same order of the high rates observed in the albino snails, we may conclude that a minority of self-fertilized embryos has been produced.

The purpose of the post-exposure crossings in this study - two after the treatment with cyclophosphamide and a single crossing after the treatment with mitomycin $\mathrm{C}$ - was to confirm the genetic nature of the induced malformations. A single crossing was made $24 \mathrm{~h}$ after the end of the exposure to mitomycin $\mathrm{C}$ considering that, despite of the lack of data on its toxicokinetics in Biomphalaria, this chemical is a direct mutagen. In fact, mitomycin $\mathrm{C}$ also 
requires enzymatic activation to exert its biological effect, but the metabolic biorreduction is carried out very quickly and can occur in several cellular types $[28,29]$. Cyclophosphamide, in contrast, requires several metabolic steps and a system of mixed function oxidases [30,31]. These crossings were sufficient to detect the mutagenicity of both compounds. The stages of gametogenesis in gastropods are, essentially, similar to those observed in mammals and morphologically well characterized [26,32,33], but its chronology has not been established. Thus, additional crossings to determine the affected stages of spermatogenesis were not done; these effects were estimated from the time-response curve of ovogenesis obtained by the analysis of the wild-type snails offspring. We assumed that the effects on ovogenesis are similar to those occurred on spermatogenesis, since pre-meiotic phases of female gametogenesis are present in the adult snail [26]. Temporal graphs showed that cyclophosphamide affected germ cells of B. glabrata at later phases of ovogenesis, probably after meiosis (Fig. 8). For mitomycin C, the effects of toxic concentrations of were observed at all stages, but with the lowest concentration, only the early stages of ovogenesis were affected (Figs. 9 and 10). These results are in agreement with studies on rodents using the dominant lethal test. Post-meiotic stages of gametogenesis were the most sensitive to the induction of damage by cyclophosphamide [34]. Ehling [35] treated mice with three doses of mitomycin $\mathrm{C}$ and obtained different time-response curves for each one. Germ cells at later phases of spermatogenesis were affected only at the highest dose: $7.0 \mathrm{mg} / \mathrm{kg}$ b.w. ( $\mathrm{LD}_{50}$ for mice is $8.0 \mathrm{mg} / \mathrm{kg}$ b.w.). Comparing mitomycin $\mathrm{C}$ with other inducers of dominant lethal mutations, Witt and Bishop [36] emphasized the induction of higher frequencies of lethal mutations in pre-meiotic stages of gametogenesis, a specific effect of mitomycin $\mathrm{C}$, attributed to the inhibition of DNA synthesis.

Regarding the sensitivity of the system, our results showed that the ability of the dominant lethal test with B. glabrata to detect mutagens was comparable to other aquatic organisms.

The minimum effective concentration of $3.6 \times 10^{-5}$ $\mathrm{M}$ of cyclophosphamide in B. glabrata was smaller than those required by other organisms tested. A concentration of $10^{-3} \mathrm{M}$ was able to induce ef- fects such as SCE in larvae and embryos of marine polychaetes Neanthes arenaceodentata [37] and Platynereis dumerilii [38]; a concentration of $3.2 \times 10^{-4} \mathrm{M}$ produced chromosome aberrations in the latter [38].

The minimum effective concentration of mitomycin $\mathrm{C}$ in B. glabrata was $10^{-6} \mathrm{M}$. Dominant lethal mutations were induced in the marine fish $O$. latipes with $7.5 \times 10^{-6} \mathrm{M}$ [7]. In embryos of marine fish Rhodeus ocellatus, $6 \times 10^{-6} \mathrm{M}$ of mitomycin C produced chromosome aberrations and micronuclei were induced with $6 \times 10^{-5} \mathrm{M}$ [39]. In the marine polychates, $N$. arenaceodentata and $P$. dumerilii, the minimum effective doses of mitomycin $\mathrm{C}$ were $5 \times 10^{-6}$ and $6 \times 10^{-6} \mathrm{M}$ to induce SCE and $3.2 \times 10^{-6} \mathrm{M}$ for chromosome aberrations [37,38]. In embryos of two species of sea urchin, Hemicentrotus pulcherrimus and Clyperaster japonicus, micronuclei and alterations in embryonic development were induced with $8 \times 10^{-6}$ and $10^{-4} \mathrm{M}[40]$.

The dominant lethal test in B. glabrata proposed in this work is easy to perform, efficient, specific and sensitive in the evaluation of germ cell mutations induced by reference mutagens. The possibility of expanding its use to environmental biomonitoring studies seems very promising and worth trying.

\section{Acknowledgements}

The authors thank Dr. M.N. Rabello-Gay for helpful suggestions during the course of this work and L.F. Tallarico, P.A. Miyasato for the technical assistance.

\section{References}

[1] J.D. Cooney, Freshwater tests, in: G.M. Rand (Ed.), Fundamentals of Aquatic Toxicology, Taylor \& Francis, Washington, DC, 1995, pp. 71-102.

[2] V.S. Houk, The genotoxicity of industrial wastes and effluents, Mutat. Res. 277 (1992) 91-138.

[3] L.D. Claxton, V.S. Houk, T.J. Hughes, Genotoxicity of industrial wastes and effluents, Mutat. Res. 410 (1998) 237242.

[4] P.A. White, J.B. Rasmussen, The genotoxic hazards of domestic wastes in surface waters, Mutat. Res. 410 (1998) 223-236.

[5] M.H. Depledge, The ecological significance of genotoxicity in marine invertebrates, Mutat. Res. 399 (1998) 109-122. 
[6] N. Egami, A. Shimada, A. Hama-Furukawa, Dominant lethal mutation rate after $\gamma$-irradiation of the fish Oryzias latipes, Mutat. Res. 107 (1983) 265-277.

[7] A. Shimada, N. Egami, Dominant lethal mutations induced by MMS and mitomicyn C in the fish Oryzias latipes, Mutat. Res. 125 (1984) 221-227.

[8] A. Shimada, A. Shima, Combination of genomic DNA fingerprinting into medaka specific-locus test system for studying environmental germ-line mutagenesis, Mutat. Res. 399 (1998) 149-165.

[9] A.N. Jha, Use of aquatic invertebrates in genotoxicological studies, Mutat. Res. 399 (1998) 1-2.

[10] J. López-Barea, C. Pueyo, Mutagen content and metabolic activation of promutagens by molluscs as biomarkers of marine pollution, Mutat. Res. 399 (1998) 3-15.

[11] O.S. Carvalho, Intermediate hosts of Schistosoma mansoni in Brazil, Mem. Inst. Oswaldo Cruz 87 (suppl. IV) (1992) 307-309.

[12] T. Camey, N.H. Verdonk, The early development of the snail Biomphalaria glabrata (Say, 1818) and the origin of the head organs, Neth. J. Zool. 20 (1970) 93-121.

[13] T. Kawano, K. Okazaki, L. Ré, Embryonic development of Biomphalaria glabrata (Say, 1818) (Mollusca, Gastropoda, Planorbidae): a practical guide to the main stages, Malacologia 34 (1-2) (1992) 25-32.

[14] T. Kawano, L.C.G. Simões, Efeito da Stevia rebaudiana em Biomphalaria glabrata (Say, 1818), Rev. Brasil. Biol. 46 (3) (1986) 555-562.

[15] L. Ré, T. Kawano, Effects of Laurus nobilis (Lauraceae) on Biomphalaria glabrata (Say, 1818), Mem. Inst. Oswaldo Cruz 82 (suppl. IV) (1987) 315-320.

[16] K. Okazaki, T. Kawano, Cytogenetic effects of ${ }^{60}$ Co gamma radiation on Biomphalaria glabrata (Say, 1818) embryos, Caryologia 44 (2) (1991) 121-136.

[17] T. Kawano, L.C.G. Simões, J. Marques, Biomphalaria glabrata (Say, 1818): efeitos morfogenéticos do sulfato de nicotina, Rev. Brasil. Biol. 53 (4) (1992) 539-547.

[18] M.M. Yamamoto, T. Kawano, M.C.M. Young, E.P. Chu, M. Haraguchi, K. Hiroki, Molluscicidal activity of three Brazilian plant species, Fitoterapia LXVII (1) (1996) 59-62.

[19] A.J. Bateman, Testing chemicals for mutagenicity in a mammal, Nature 5032 (1966) 205-206.

[20] I. Nabih, A.Z.A. El Hamid, Biochemical studies on the genetic material of fresh water snails, intermediate hosts of schistosomiasis-II. Effect of a chemical mutagen, cyclophosphamide, on the chemical nature of deoxyribonucleic acid, Cell. Mol. Biol. 30 (2) (1984) 125-127.

[21] W.L.M. Geilenkirchen, Cell division and morphogenesis of Limnaea eggs after treatment with heat pulses at successive stages in early division cycles, J. Embriol. Exp. Morphol. 16 (2) (1966) 321-337.

[22] H.B. Newcombe, J.F. McGregor, Major congenital malformations from irradiations of sperm and eggs, Mutat. Res. 4 (1967) 663-673.

[23] W.L. Paraense, Auto-fecundação e fecundação cruzada em Australorbis glabratus, Mem. Inst. Oswaldo Cruz 53 (2-4) (1955) 277-284.
[24] F.M. Díaz-Méndez, A. Rodríguez-Ariza, J. Usero-García, C. Pueyo, J. López-Barea, Mutagenic activation of aromatic amines by molluscs as a biomarker of marine pollution, Environ. Mol. Mutagen. 31 (1998) 282-291.

[25] R. Singh, R.A. Agarwal, Cyclophosphamide as a potential chemosterilant for harmful snails, Acta Pharmacol. Toxicol. 49 (1981) 195-199.

[26] M.R. Dohmen, Gametogenesis, in: A.S. Tompa, N.H. Verdonk, J.A.M. Van der Biggelaar (Eds.), The Mollusca, vol. 3, Academic Press, London, 1983, pp. 1-47.

[27] J.G. Vernon, J.K. Taylor, Patterns of sexual roles adopted by the schistosome-vector snail Biomphalaria glabrata (Planorbidae), J. Moll. Stud. 62 (1996) 235-241.

[28] V. J Spanswick, J. Cummings, J.F. Smyth, Current issues in the enzymology of mitomycin $\mathrm{C}$ metabolic activation, Gen. Pharmacol. 31 (4) (1998) 539-544.

[29] P. Morales-Ramirez, T. Vallarino-Kelly, G. Anguiano-Orozco, R. Rodríguez-Reyes, Pharmacokinetic parameters of genotoxic activity inferred from the comparison of the kinetics of MN-PCE induced by chemical agents and ionizing radiation, Mutat. Res. 391 (1997) 127-134.

[30] A. Korolkovas, J.H. Burckhalter, Química Farmacêutica, Guanabara S.A.R.J. Rio de Janeiro, 1988, 783 pp.

[31] P. Calabresi, B.A. Chabner, Fármacos Antineoplásicos, in: L.S. Goodman, A. Gilman (Eds.), As Bases Farmacológicas da Terapêutica, MacMillan, New York, 1990, pp. 805-840.

[32] M. de Jong-Brink, A. de Witt, G. Kraal, H.H. Boer, A light and electron microscope study on oogenesis in the freshwater pulmonate snail Biomphalaria glabrata, Cell Tissue Res. 171 (1976) 195-219.

[33] M. de Jong-Brink, H.H. Boer, T.G. Hommes, A. Kodde, Spermatogenesis and the role of Sertoli cells in the freshwater snail Biomphalaria glabrata, Cell Tissue Res. 181 (1977) 37-58.

[34] D. Anderson, J.B. Bishop, R.C. Garner, P.O. OstroskiWegman, P.B. Selby, Cyclophosphamide: review of its mutagenicity for an assessment of potential germ cell risks, Mutat. Res. 330 (1995) 115-181.

[35] U.H. Ehling, Comparison of radiation and chemically induced dominant lethal mutations in male mice, Mutat. Res. 11 (1971) $35-44$.

[36] K.L. Witt, J.B. Bishop, Mutagenicity of anticancer drugs in mammalian germ cells, Mutat. Res. 355 (1996) 209-234.

[37] G.G. Pesch, C.E. Pesch, A.R. Malcom, Neanthes arenaceodentata, a cytogenetic model for marine genetic toxicology, Aquat. Toxicol. 1 (1981) 301-311.

[38] A.N. Jha, T.H. Hutchinson, J.M. MacKay, B.M. Elliot, D.R. Dixon, Development of an in vivo genotoxicity assay using the marine worm Platynereis dumerilii (Polychaeta: Nereidae), Mutat. Res. 359 (1996) 141-150.

[39] M. Hayashi, T. Ueda, K. Uyeno, K. Wada, N. Kinae, K. Saotome, N. Tanaka, A. Takai, Y.F. Sasaki, N. Asano, T. Sofuni, Y. Ojima, Development of genotoxicity assay systems that use aquatic organisms, Mutat. Res. 399 (1998) 125133.

[40] K. Saotome, T. Sofuni, M. Hayashi, A micronucleus assay in sea urchin embryos, Mutat. Res. 446 (1999) 121-127. 